\title{
Novel Vitreous Modulators for Pharmacologic Vitreolysis in the Treatment of Diabetic Retinopathy
}

\author{
Elaine de Paula Fiod Costa ${ }^{1}$, Eduardo B. Rodrigues ${ }^{1}$, Michel E. Farah ${ }^{1}$, Jerry Sebag ${ }^{2}$ and \\ Carsten H. Meyer ${ }^{3, *}$
}

${ }^{I}$ Department of Ophthalmology, Federal University of São Paulo, São Paulo, Vision Institute (IPEPO), Brazil; ${ }^{2}$ VMR Institute, Huntington Beach, California; Doheny Eye Institute, University of Southern California, Los Angeles, CA, USA; ${ }^{3}$ Department of Ophthalmology, University of Bonn, Germany

\begin{abstract}
Vitreous constitutes about $80 \%$ of the volume of the human eye. It is an extended extracellular matrix that is composed of collagen, hyaluronan, and other extracellular matrix molecules, but mostly water. In both health as well as disease, especially diabetic retinopathy (DR), special attention should be drawn to the posterior vitreous cortex and its relation to the retinal surface. The important role of vitreous in the pathogenesis of proliferative DR has already been demonstrated by several experimental and clinical studies. Thus, vitreoretinal separation by pharmacologic vitreolysis and/or removal by surgical means are appropriate approaches to interrupt the pathogenic contribution of vitreous and prevent progression of diabetic retinopathy to more advanced stages. This review describes various aspects of the molecular morphology and structural anatomy of vitreous and the vitreoretinal interface, as well as the role of vitreous in the pathophysiology of DR. Lastly, this treatise provides a comprehensive analysis of novel vitreous modulators for pharmacologic vitreolysis in the treatment of DR. Microplasmin is currently the most promising approach to treat vitreoretinal traction by pharmacologic vitreolysis.
\end{abstract}

Keywords: Diabetes, diabetic retinopathy, vitreous, diabetic vitreopathy, pharmacologic vitreolysis.

\section{MOLECULAR MORPHOLOGY OF VITREOUS}

Vitreous is a unique extracellular matrix formed by a complex macromolecular network. Although it has a gel-like structure, the transparent gel vitreous is composed primarily of water $(98 \%)$. Yet, its viscosity is approximately twice that of water, mainly due to the presence of glycosaminoglycans (GAGs), primarily hyaluronan (HA), which interact with collagen, forming the three dimensional organization of the vitreous gel [1,2].

In fact, recent studies showed that although the viscosity of the vitreous gel is variable, it maintains several times more viscous than water, balanced salt solution (BSS) or even aqueous humour. Lee et al. [3] measured the viscosity of human vitreous gel with $300-2.000 \mathrm{cP}$, while the viscosity of water is $1 \mathrm{cP}$.

At the ultrastructural level, HA and type II collagen are believed to be the principal components of the vitreous associated with a small amount of sulfated or unsulfated GAGs [4]. HA was first isolated from bovine vitreous in 1934 by Meyer and Palmer [5] and is a major macromolecule of vitreous. Its concentration is estimated between 65 and 400 $\mathrm{mg} / \mathrm{ml}$ and contains an average molecular weight of $3-4.5 \mathrm{x}$ $10^{6}$ Daltons. It is a linear, three-fold helix of a repeating disaccharide (glucuronic acid $\beta(1,3)-N$-acetylglucosamine) moieties and also contains a covalently linked proteoglycan

\footnotetext{
*Address correspondence to this author at the Ernst-Abbe-Street 2, Department of Ophthalmology, University of Bonn, 53127 Bonn, Germany; Tel:++49 (228) 287-19075; Fax: ++49 (228) 287-15603;

E-mail: meyer_eye@yahoo.com
}

protein core. HA plays a pivotal role in stabilizing the vitreous gel and prevents collagen fibrils from aggregating [6-8]. Among sulfated GAGs, the main vitreous constituent is chondroitin sulfate (CS) which is usually found attached to core proteins to form proteoglycans (type IX collagen and versican) in a ladder-like configuration, maintaining collagen fibril separation. Also, other molecules such as fibrillins, opticin, and vit1 may play a role in organizing the threedimensional network that achieves the physiologic functions of media clarity and shock absorption [7, 9, 10]. Of these minor constituents, Opticin may be the most important since it is believed to play a role in both HA-collagen interaction as well as maintenance of vitreo-retinal adhesion [6]. Opticin may also play an important role in maintaining vitreous transparency (Fig. (1)) by dint of its ability to inhibit the migration and proliferation of various cells.

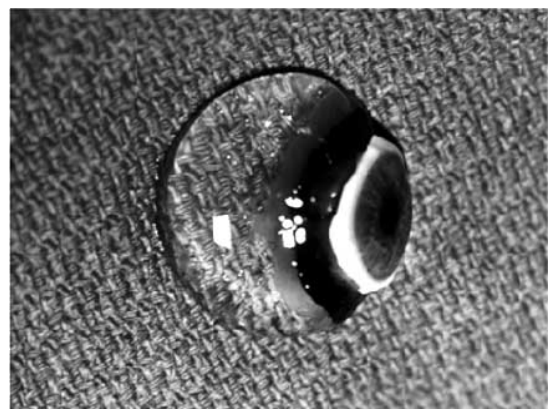

Fig. (1). Human vitreous dissected of the sclera, choroid, and retina. From Sebag J: The Vitreous -Strcuture, Function, and Pathobiology. Springer-Verlag, New York, 1989. Specimen courtesy of New England Eye Bank.

(c) 2011 Bentham Science Publishers Ltd. 
Whereas, HA imparts viscoelasticity to vitreous, collagen is responsible for its structural frame. Collagen concentration in the vitreous gel is approximately $300 \mathrm{ug} / \mathrm{ml}$, consisting mostly of type II collagen, but also a hybrid of collagen types V/XI and type IX at a molar ratio of $75: 10: 15[1,2]$. These collagen molecules are organized into a triple polypeptide chain folding in its characteristic triple helical configuration and assembled into fibrils with a rope-like structure that have a diameter of $7-28 \mathrm{~nm}$ [9]. The supramolecular organization of the vitreous gel consists of a meshwork of collagen fibrils interspersed with arrays of HA molecules [2]. Collagen type V/XI reside in the core, while collagen type II surrounds the core, and type IX collagen is mainly found on the surface of the fibrils [9].

\subsection{Ultrastructure of the Vitreo-Retinal Interface}

Although the exact nature of vitreoretinal adhesion is unknown, it most probably results from the biophysical properties of the extracellular matrix molecules found at the vitreoretinal interface $[1,2,4,11]$. This interface includes the inner limiting lamina (ILL) of the retina and the posterior vitreous cortex, a 100-um thick layer of collagen fibrils running parallel to the retinal surface [12]. The posterior vitreous cortex is an important structure in the human with respect to both normal physiology [1] and several pathologic conditions of the posterior segment [1,4] (Fig. (2)).

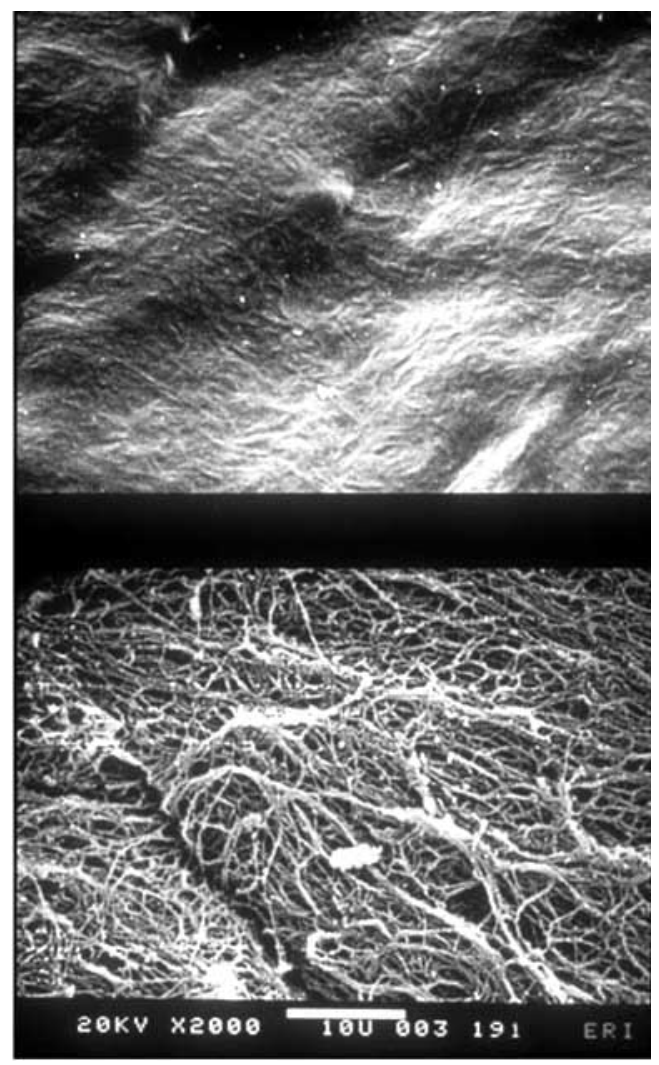

Fig. (2). Scanning electron microscopy of the human vitreo-retinal interface demonstrates the inner (anterior) aspect of the ILL (top photo), which is composed primarily of type IV collagen, and the outer (posterior) aspect of the posterior vitreous cortex (bottom photo), whose fibrils are primarily composed of type II collagen. (bar $=10$ microns)
The ILL is the trilaminar basal lamina of Müller cells, consisting of laminin, fibronectin, types I and IV collagen, proteoglycans, laminin, fibronectin and other glycoconjugates, that are thought to bridge and bind collagen fibers between the posterior vitreous cortex and the ILL, acting as a molecular glue between vitreous and retina. Laminin and fibronectin are thought to play a role in stabilizing vitreoretinal adhesion [13]. In the eye, fibronectin is present in the ILL and the vitreous, whereas laminin is located only in the ILL [14]. Fibronectin exists on the surface of most cells and extracellular matrices as well as basement membranes e.g. ILL [15]. It has a high affinity for extracellular matrix components such as collagen [16]. Laminin, on the other hand, is located only on the ILL, where it binds to and promotes the adhesion of cells to collagen type IV [17-20]. At the vitreous base there are unbreakable adhesions resulting from vitreous collagen fibrils passing perpendicular through the ILL and intertwining with collagen on the retinal side of the interface. Posterior pole adhesion of the vitreous to the retina, however, is mediated by molecular interactions between the PVC and the ILL $[1,4,11,12,21]$.

\section{AGING AND POSTERIOR VITREOUS DETACH- MENT}

In the posterior vitreous cortex, which is responsible for the retinal pathology that most often requires surgical intervention, the collagen fibers are much more densely packed and course in a direction roughly parallel to the inner retina. During aging, vitreo-retinal adhesion weakens, probably related to typical changes of basal lamina aging and the effects of free radicals, which are generated by incident light and cell metabolism in the tissues surrounding vitreous [21]. Within the vitreous body there is progressive increase in the volume of liquefied vitreous (synchysis) [22] leading to ultimate collapse of the vitreous body (syneresis) [23]. Clinically, synchisis is an important phenomenon, because it ultimately results in posterior vitreous detachment (PVD), which occurs when there is concurrent weakening at the vitreo-retinal interface. In most cases, vitreous syneresis results in complete and innocuous vitreo-retinal separation, or PVD. If there is insufficient weakening at the vitreo-retinal interface, anomalous $P V D$ [24] can induce potentially serious pathologic events at the vitreoretinal interface (e.g. retinal tears and retinal detachment, intravitreal hemorrhage, or various vitreo-maculopathies) [22].

\section{PATHOPHYSIOLOGY OF DIABETIC VITREOPA- THY \& RETINOPATHY}

\subsection{The Role of Vitreous in Diabetic Retinopathy}

Several experimental and clinical studies demonstrated that the vitreous plays an important role in the pathogenesis of proliferative diabetic vitreo-retinopathy (PDVR). Retinal vessels are normally excluded from the vitreous cavity, however in PDVR there are proliferating vessels at the vitreoretinal interface and into the posterior vitreous cortex, suggesting at least a facilitating role if not an active role for vitreous in the angiogenic process [25]. There is also evidence that the vitreous of patients with DR contains elevated levels of growth factors synthesized and transported from retinal cells into the vitreous cavity [26-28]. This may be due to the 
fact that in addition to the ischemia induced by inadequate retinal blood flow, the abnormalities in vitreous biochemistry induced by diabetes interferes with the transport of oxygen from the ciliary body to the inner retina, worsening retinal ischemia. It is known that the vitreous of humans with PDVR contains elevated levels of advanced glycation endproducts [29]. Thus, in PDVR intravitreal proteins that normally inhibit angiogenesis may also undergo marked nonenzymatic glycation impeding their ability to inhibit angiogenesis and contributing to the pathogenesis of PDVR [30, 31].

Sebag et al. [29, 31, 32] investigated the effects of diabetes on human vitreous biochemistry as well as the structural consequences of these biochemical abnormalities, and termed the phenomenon Diabetic Vitreopathy [31]. The findings suggest that elevated levels of glucose in vitreous induce the formation of advanced glycation end-products, cross-linking of vitreous collagen, and excess liquefaction which without dehiscence at the vitreo-retinal interface can place traction upon the retina and any structures at the vitreoretinal interface, such as neovascular membranes. It is known from the work of Faulborn and Bowald, who studied the vitreo-retinal interface in humans with PDVR, that new vessels arising from the optic disc and retina grow into the posterior vitreous cortex [25]. Thus, in addition to providing a scaffold for the migration and proliferation of retinal capillary endothelial and other vasoproliferative cells, the posterior vitreous can influence the course of PDVR in two ways: Firstly, rheologic changes within the gel of a diabetic patient may induce precocious senescence and syneresis without concurrent dehiscence at the vitreo-retinal interface. This will place traction upon the new blood vessels and aggravate the process of neovascularization by stimulating further growth. Secondly, the posterior vitreous cortex, which consists of extracellular matrix proteins, mainly fibronectin and laminin [33], is organized in lamellae which can split, a phenomenon known as vitreoschsis [34]. Studies have shown an increased incidence of vitreoschsis in patients with PDVR [35]. The development of vitreoschsis could thus rupture new vessels that have grown into the posterior vitreous cortex, inducing vitreous hemorrhage. Indeed, the typical 'boatshaped' hemorrhage see in these patients is likely hemorrhage into a vitreoschisis cavity (Fig. (3)). Previous clinical reports indicated that PDVR is rare if the posterior vitreous is completely detached from the retinal surface, as frequently found after pan retinal photocoagulation [36] and surgical vitrectomy, since the scaffold for proliferating cells is destroyed.

Diabetes also induces a breakdown of the blood-retinal barrier, leading to an accumulation of serum proteins, especially fibronectin (up to 10-fold) at the vitreoretinal interface [33]. Since fibronectin mediates the adhesion and migration of proliferating endothelial cells [37], this can promote neovascualrization. In the advanced stages of DR the vitreous gel contracts, leading to vitreous hemorrhage due to the rupture of the proliferative vessels, as well as traction retinal detachment. Shrinkage of the vitreous indicates cross-linking of collagen fibrils [38]. Angiogenic cells migrate and then neovascular proliferation arises in this vicious cycle.

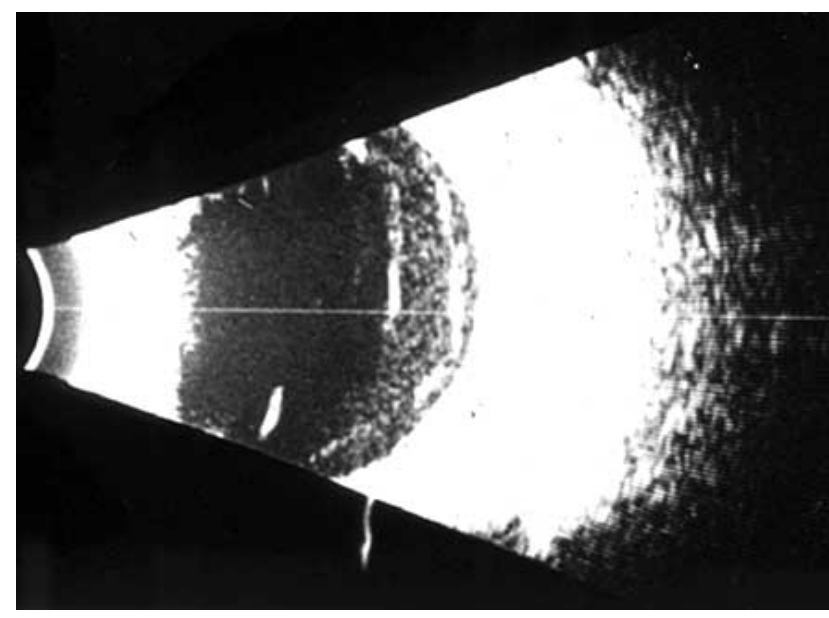

Fig. (3). Vitreoschisis in PDVR with vitreous hemorrhage loculated between the two walls of the vitreoschisis cavity. Courtesy of Ron Green, MD, University of Southern California.

\subsection{Clinical Staging of Proliferative Diabetic Vitreo- Retinopathy}

As the vitreous has a defined role in the pathogenesis of DR, vitreous removal by enzymatic or surgical means is an appropriate technique to interrupt this process and to prevent progression to advanced stages. Various studies have demonstrated that vitrectomy earlier in the course of the disease prevents the onset of severe complications [39, 40]. However, a good postoperative visual outcome is difficult to predict even though various factors like preoperative visual acuity, short duration of visual loss, absence of iris neovascularization, a clear lens and partial panretinal photocoagulation are known [39]. Therefore a classification of proliferative diabetic vitreoretinopathy (PDVR) including the status of the retina and the vitreous was established by Kroll et al [41]. Since the posterior vitreous cortex is mainly responsible for this disease entity, the term PDR has been changed to PDVR in analogy to the term proliferative vitreoretinopathy $[31,41,42]$. Stage $\mathbf{A}$ is characterized by proliferative changes on the retinal surface throughout the retina, however the retina is totally attached. Stage B consists of circumscribed tractional retinal detachment around the optic disc and at the temporal arcades, as a result of shrinkage of the vitreoretinal interface. However, the macula is attached, so good visual acuity is still present. Stage $\mathbf{C}$ is characterized by tractional retinal detachment involving the macula. Due to macular detachment visual function is always reduced (Fig. (4)). This classification has an important impact as a prognostic value regarding postoperative visual outcome [43].

In addition, there may be strong adhesions at the margin of the optic disc resulting in vitreopapillary traction. The posterior vitreous cortex is particularly adherent to the optic disc and can exert significant force resulting in vitreopapillary traction. Recent studies [44] have shown that $87.5 \%$ of patients with a macular hole have vitreo-papillary adhesion, in contrast to macular pucker, where only $17.9 \%$ had vitreopapillary adhesion $(\mathrm{P}<0.00005)$. Vitreopapillary traction has been proposed as a possible cause of temporary or chronic functional impairment. Tractional forces may elon- 


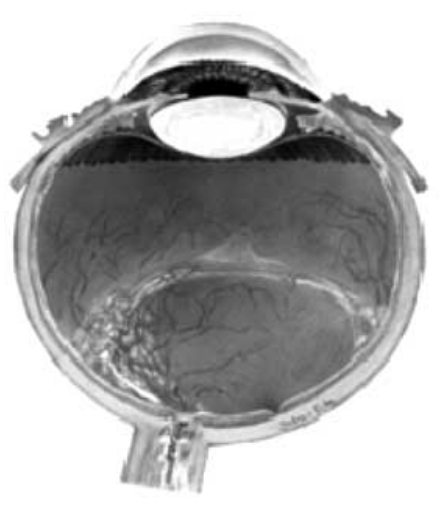

Stage A

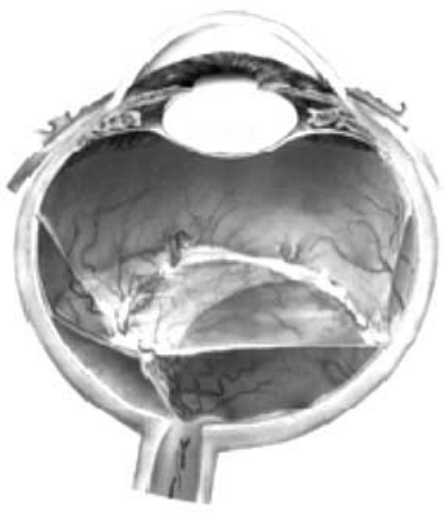

Stage B

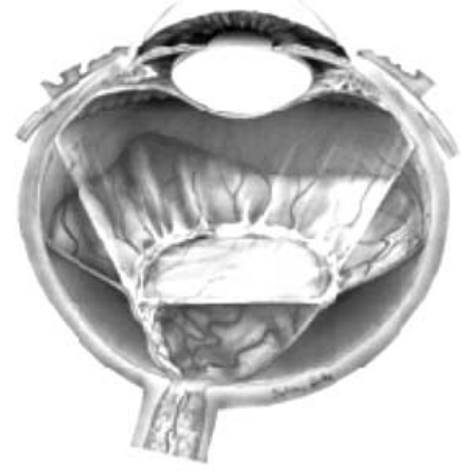

Stage C

Fig. (4). Classification of proliferative diabetic vitreoretinopathy (PDVR). Stage A -with proliferative changes on the retinal surface throughout the retina; Stage B - circumscribed tractional retinal detachment around the optic disc and at the temporal arcades without macular detachment; Stage C - tractional retinal detachment involving the macula.

gate the optic nerve fiber bundles, which may consecutively lead to their thinning. The distortion of normal anatomy could interfere with axoplasmatic transport leading to a reduction of axolemmal transmission, which manifests in abnormal VEP [45]. Additionally, vitreopapillary traction may reduce the diameter of the blood vessels nourishing the optic nerve head, causing ischemia of the papilla. Both, decreased axoplasmatic transport in the optic nerve fibers (neurogenic) as well as a mechanical restriction of blood flow (vasogenic) seem to be reversible after release of vitreous traction by vitrectomy [45-48].

\subsection{The Role of Vitreous in Diabetic Macular Edema}

The posterior vitreous cortex is also believed to play a role in the pathogenesis of diabetic macular edema (DME) [49-51]. In Boston, Nasrallah and associates [52] determined a significantly higher incidence of an attached posterior vitreous in eyes with DME than in eyes without DME. These findings suggest an important role of the posterior vitreous in DME. A complete PVD, occurring in the majority of healthy individuals during aging, may also have a protective effect against more advanced stages of diabetic retinopathy in diabetic patients. However, some diabetic cases may develop liquefaction with insufficient dehiscence of the posterior vitreous cortex from the retina, thus preventing a complete separation from the retinal surface also known as "Anomalous PVD” [24]. The sequelae of anomalous PVD vary, depending on whether the firmly adherent posterior vitreous cortex that remains full or in partial thickness on the retina, known as vitreoschisis [34], a common phenomenon in macular holes and macular pucker [53]. Hikichi and associates [54] investigated the natural course of DME associated with the vitreomacular traction (VMT), presumably in an antero-posterior direction. They observed spontaneous resolution of the edema in $55 \%$ in eyes with vitreomacular separation, compared to $25 \%$ in eyes with persistent VMT. A taut posterior vitreous cortex may also exert tangential traction thereby inducing DME [55].

\subsubsection{Mechanisms of Vitreo-Maculopathy in Diabetic Macular Edema}

\section{a) Mechanical Release Theory}

Breakdown of the blood-retinal-barrier (BRB) accumulates a high concentration of intravitreal serum-derived chemoattractants, stimulating cellular migration on the attached posterior vitreous cortex. Contraction of these cells may induce tangential traction and exacerbation of DME [56]. Sebag and associates suggested that the abnormal cross-linking induced by non-enzymatic glycation might affect the collagen architecture structure in diabetic vitreous, inducing vitreomacular traction (VMT) $[32,57,58]$. Steffanson [15] explained the effects of VMT on retinal edema in the light of the Newton's third law [59]. It is known that to any action (force) there is always an opposite and equal reaction (counter-force), thus a vitreomacular traction (VMT) will always met by an force in the opposite direction in the retinal tissue causing a reduced pressure in the tissue of the retina. This lower tissue pressure may changes the difference between the hydrostatic pressure in the blood vessels and the tissue itself leading to macular edema. Since 1896 we know by Starling law: "there is always a balance between the hydrostatic pressure in the blood of the affected capillaries and the osmotic attraction the corresponding adjacent fluids. A release of the traction will therefore change equilibrium increasing the pressure in the tissue, thus lowering the hydrostatic pressure gradient and reduce which will reduce the flux of water from the blood capllaries into neuroretinal tissue and edema formation (see Starling's law below).

\section{b) Chemical Release Theory}

Ischemia in retinal tissue and a breakdown of the bloodretinal barrier elevates the concentration of numerous angiogenic growth factors in the retina and the premacular posterior vitreous cortex exacerbating DME. A removal of the posterior vitreous cortex and gel by vitrectomy may release and wash out these preretinal growth factors, as well as enhance the diffusion of all molecules to and from the retina. Molecules that are produced in the retina, such as vascular 
endothelial growth factor (VEGF) may be cleared at a higher rate in the fluid vitreous cavity leading to a reduced VEGFconcentration. Oxygen is normally transported by diffusion and convection from the anterior chamber (where the $\mathrm{PO}_{2}$ is normally higher than at the retina) to the posterior segment, resulting in anterior segment and iris hypoxia. However, in the vitrectomized-lensectomized eye there is the oxygen transport between the anterior and posterior segments of the eye were increased compared to the intact eye [60, 61]. The consecutive clearance of VEGF and additional cytokines may help to prevent macular edema and retinal neovascularization in ischemic retinopathies. Conversely, growth factors such as VEGF could be transported more readily from the retina to the iris.

\section{SURGICAL INDUCTION OF POSTERIOR VITRE- OUS DETACHMENT}

Previous investigations reported a salubrious impact of pars plana vitrectomy (PPV) on DME [49-52, 54]. Vitrectomy with removal of the premacular posterior vitreous cortex may resolve DME and improve vision in patients who previously failed to respond to conventional laser treatment. It is not known whether this would also be the case in comparison to intravitreal anti-VEGF injections. The most relevant mechanism for the improvement of the edema is the relief of vitreomacular traction (Fig. (5)). Nevertheless, both trans-vitreal oxygenation and improved growth factor diffusion away from the macula have been suggested as potentially beneficial effects. Also, other systemic and local factors including duration of edema, extent of ischemia and exudation, and extent of laser may result in permanent photoreceptor and capillary damage, which precludes anatomic or visual benefit. Most of the studies on the subject of vitrectomy for DME are retrospective and uncontrolled but strongly suggest a benefit in terms of improved acuity and reduced macular thickness following vitrectomy. The proportion of eyes that improved more than two lines in these studies ranged from 50 to $78 \%$ [62]. Yamamoto and associates [63] reported an improvement of $60 \%$ in visual acuity after the vitrectomy in patients with DME, PVD and epiretinal membranes. Notwithstanding, less consistent results were found in prospective studies as reported by DRCR.net group (Diabetic Retinopathy Clinical Research Network 2009) [64] which analyzed 87 eyes with at least moderate vision loss $(20 / 63-20 / 400)$ and vitreomacular traction. After 6 months of follow-up, $38 \%$ eyes improved 10 letters and $22 \%$ had worsened 10 letters in the ETDRS chart. A few randomized controlled trials did not suggest either a clear benefit from surgery [64].

Patient selection for surgery on the basis of partial vitreomacular separation on OCT or clinical signs of traction such as an epiretinal membrane or taut thickened posterior vitreous cortex has been reported to be associated with a modest improvement in prospective studies but this has not been subjected to controlled study [62].

\section{PHARMACOLOGIC VITREOLYSIS AND THE IN- DUCTION OF PVD}

The use of enzymes in ophthalmology has a long history. Chymotryprsin was one of the first enzymes applied to pro- duce zonules disruption during intracapsular cataract surgery. In vitreous, hyaluronidase was employed as early as 1949 [65] and collagenase in 1973 [66]. Experimentally, if HA is enzymatically removed, the gel will shrink but its structure is not destroyed. On the other hand, if collagen is removed, the remaining HA persists as a viscous solution. Thus, the ideal approach to crafting pharmacologic means to manipulate the gel state of the vitreous and its attachment to the retina would be to first definitively characterize the molecular nature of these phenomena and to then design precise methods to alter these states [24].

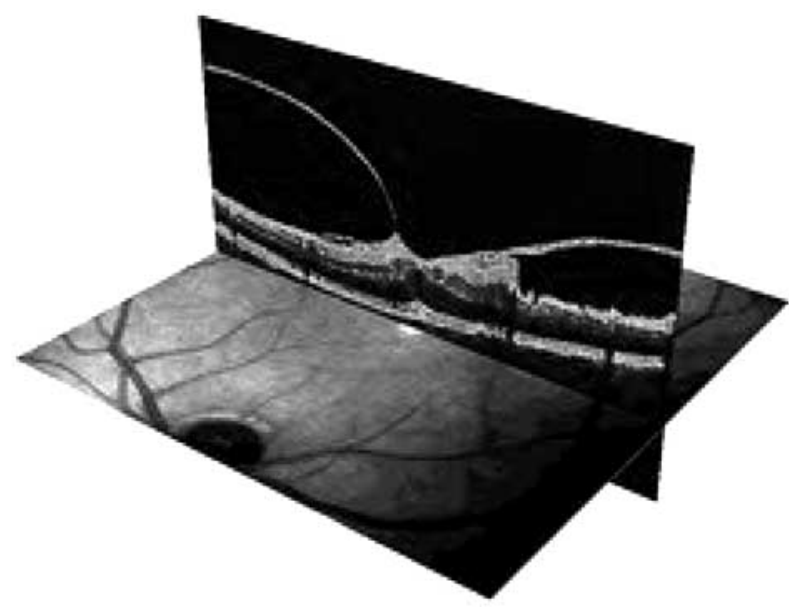

Fig. (5). Vitreomacular traction on high resolution optical coherence tomography (OCT) shows the convex elevation of the neuroretina leading to visual distortion and reduced visual acuity in a patient with DME.

With the idea of pharmacologic manipulation of the vitreous gel and its attachment to the retina, a variety of approaches have been attempted to date. In order to prevent an anomalous PVD, during pharmacologic vitreolysis the first step should be to induce the vitreoretinal dehiscence to create a cleavage plane between the retinal surface and the posterior vitreous cortex, and then induce collapse (syneresis) via liquefaction (synchisis) inducing PVD more safely and completely than can currently be achieved by mechanical means $[11,55,67,68]$. Induction of liquefaction without adequate dehiscence at the vitreo-retinal interface might actually cause anomalous PVD and worsen the clinical state.

Pharmacologic vitreolysis refers to the use of agents that can liquefy the gel structure of the vitreous (synchisis) and weaken the adherence of the posterior vitreous cortex to the ILL of the retina [67]. The goal of pharmacologic vitreolysis is to manipulate the vitreous macromolecules to induce both liquefaction, as well as dehiscence at the vitreyretinal interface. Enzymes have been employed for more than 60 years.

A purified preparation of the former agent has failed Phase III FDA clinical trials of its efficacy to clear vitreous hemorrhage without vitrectomy.

\subsection{Pharmacologic Vitreolysis as Adjunct to Surgery}

There are several reasons to pursue enzymatic-assisted vitreoretinal surgery. First, some retinal diseases, which are currently treated with mechanical manipulation of the vitreo- 
retinal interface, may be managed more safely by pharmacologic vitreolysis [69]. Second, pharmacologic vitreolysis may achieve better anatomic and therefore possibly better functional results by creating a cleaner cleavage plane between the posterior vitreous cortex and the retina than is conventionally achieved by surgery $[55,69]$. This is of particular importance in eyes with incomplete removal of the cortical vitreous from the retinal surface, or in eyes with vitreoschisis, especiallly diabetic eyes [70]. Third, as incomplete PVD has been shown to be associated with both development of aggressive fibrovascular proliferation and macular edema, pharmacologic induction of complete PVD may prevent progression of DR if given before advanced stages of diabetic eye disease [55, 71]. Furthermore, pharmacologic vitreolysis may improve physiology by improved transport of molecules in the vitreous cavity. Several enzymes have been suggested as adjunctive therapy to vitreoretinal surgery, including chondroitinase, hyaluronidase, dispase, and plasmin enzyme (Table 1). Of note is that hyaluronidase and dispase were of limited success due to insufficient vitreoretinal separation or digestion of inner retinal structures leading to retinal edema [72-78].

\subsection{Terminology and Classification of Pharmacologic Vitreolysis}

The term "enzymatic vitreolysis" was originally proposed since initial attempts predominantly used enzymes as adjuncts to surgery $[79,80]$. Later the term "pharmacologic vitreolysis" was proposed [67], since vitreolysis agents were classified in "enzymatic" or "nonenzymatic" mechanisms according to their properties and action. At that time Sebag proposed that these agents could be further characterized as either nonspecific or substrate-specific agents. The former included tissue plasminogen activator [81], plasmin [82, 83], microplasmin [84, 85] and nattokinase [86]; while substratespecific agents included chondroitinase [87], dispase [76, 88] and hyaluronidase [75, 89].

Recently, Sebag has proposed an alternative classification based upon the biologic effects of the different agents, in particular whether they induce liquefaction ("liquefactants") or whether they induce dehiscence at the vitreoretinal interface ("interfactants"). Table 1 lists the different pharmacologic vitreolysis agents currently in development [90].

Table 1. Pharmacologic Vitreolysis Classification Based on Biologic Activity [90]

\begin{tabular}{|c|c|}
\hline \multicolumn{2}{|c|}{ Liquefactants (Agents that Liquefy the Gel vitreous) } \\
\hline Nonspecific & $\begin{array}{l}\text { tPA, plasmin, microplasmin, nattokinase, vitreo- } \\
\text { solve* }\end{array}$ \\
\hline Substrate specific & chondroitinase, hyaluronidase \\
\hline \multicolumn{2}{|c|}{ Interfactants (Agents that alter the Vitreoretinal Interface) } \\
\hline Nonspecific & $\begin{array}{l}\text { tPA, plasmin, microplasmin, nattokinase, vitreo- } \\
\text { solve* }\end{array}$ \\
\hline Substrate specific & dispase, chondroitinase, RGD-peptides* \\
\hline
\end{tabular}

$*$ denotes non-enzymatic agents.

\subsection{Pharmacologic Vitreolysis Agents}

\subsubsection{Enzymatic}

\section{a) Streptokinase}

Streptokinase (SK), a protein secreted by several species of streptococci, can bind and activate human plasminogen. $\mathrm{SK}$ is used as an effective and inexpensive clot-dissolving medication in some cases of myocardial infarction [91] and pulmonary embolism [92]. Streptokinase belongs to a group of medications known as fibrinolytics, and complexes of streptokinase with human plasminogen can hydrolytically activate other unbound plasminogen through bond cleavage to produce plasmin. It is supplied as a lyophilized white powder containing $25 \mathrm{mg}$ cross-linked gelatin polypeptides, $25 \mathrm{mg}$ sodium L-glutamate, sodium hydroxide to adjust $\mathrm{pH}$, and $100 \mathrm{mg}$ Albumin (Human) per vial or infusion bottle as stabilizers and is stored below $25^{\circ} \mathrm{C}$ until administered.

Cherfan et al. [93] were the first to describe the intraocular use of streptokinase, as a fibrinolytic agent to dissolve fibrinous exudates after pars plana vitrectomy. They reported no clinically detectable adverse effects following an intraocular injection of 1,000 IU of purified streptokinase. Furthermore, Baha and associates [94] evaluated the possibility of using SK to induce PVD in rabbit's eyes and its toxicity. In their study, $\mathrm{SK}$, in a dose of $1,500 \mathrm{IU} / \mathrm{mL}$, was able to induce PVD in rabbits with minimal toxic effects on the retina.

Streptokinase may also bind to plasmin and form the streptokinase-plasmin complex. This complex may generate free plasmin catalytically by hydrolysis of plasminogen and may also be converted to a streptokinase-plasmin complex with fibrinolytic activity. Plasmin has been suggested as a means to modulate vitreoretinal adhesion in animal models [81, 82, 95, 96], but only streptokinase-plasmin has been tested in a pilot human case series so far. In these studies, intravitreal injections of 0.4 activity units (AU) followed by vitrectomy did not elicit any toxic effects [71, 97-99]. Hermel et al. [100] assessed the safety range of intravitreal human streptokinase-plasmin in rabbits. Enzyme doses from $0.1-7$ activity units (AU, in $0.1 \mathrm{ml}$ ) were injected into the vitreous cavity of 35 eyes; six control eyes were injected with balanced salt solution (BSS, $0.1 \mathrm{ml}$ ). Thirty minutes after injection, a two-port vitrectomy was performed. Doses up to 3 AU were found to be safe. There may be applicability of SK use in humans should further studies prove this approach safe and effective.

\section{b) Hyaluronidase}

Hyaluronidases degrade hyaluronan by cleaving glycosidic bonds of hyaluronan and, to a variable degree, some other GAGs. Hyaluronidase may lower the viscosity of vitreous, thereby mimicking liquefaction. It was hypothesized that this may increases the diffusion rate of erythrocytes and phagocytes through the vitreous and facilitates red blood cell lysis and phagocytosis $[101,102]$ in subjects with vitreous hemorrhage. However, this eventually was proven not to work in phase III FDA trials.

Hyaluronidase is commercially available in different forms. A bovine testicular protein enzyme less purified with thimerosal as a preservative (Wydase ${ }^{\circledR}$ ) has been widely used 
in ophthalmology for approximately 40 years as a spreading or diffusing agent, most commonly to enhance the effect of injectable local anesthetics. Even though, this bovine hyaluronidase/thimerosal formulation was designed as a spreading agent and not for intravitreous injection, the first reports of hyaluronidase intraocular use performed with the bovine form. Studies by Bishop et al. [87] found a significant depolymerisation of the vitreous hyaluronan in both bovine and rabbits [103]. Whether, hyaluronidase actually can induce PVD is controversial. Harooni et al. [104]. found PVD biomicroscopically and histologically in rabbits nine weeks after administration of 10 to $20 \mathrm{U}$ hyaluronidase. Hikichi et al. [75] on the contrary found no PVD on scanning electron microscopy in rabbits 6 months after administration of $20 \mathrm{U}$ hyaluronidase. Safety studies on intravitreal bovine hyaluronidase have shown significant signs of retinal toxicity. Gottlieb and colleagues [103] reported retinal necrosis 7 days after treatment with $150 \mathrm{U}$ in rabbit eyes and Heegaard et al. [105] described a disarray of the retinal fibrillary network after administration of hyaluronidase on monkey retina.

Recently, a purified preparation of ovine hyaluronidase (Vitrase, ISTA Pharmaceuticals, Inc., Irvine, USA) failed to clear vitreous hemorrhage without vitrectomy in a phase III FDA trial. A common ocular adverse event to hyaluronidase was iritis, reaching $62.1 \%$ of the 75 IU group and retinal detachments were present in $9.5 \%$ of eyes [74]. While this agent has been proposed to induce PVD, there is little theoretical basis for this approach, because hyaluronidase alone will not likely degrade the molecules responsible for vitreoretinal adhesion. Indeed, experimental trials of hyaluronidase in rabbits failed to achieve PVD [75].

\section{c) Nattokinase (Subtilisin NAT)}

Nattokinase is a serine protease composed of 275 amino acids produced by fermentation of the Bacillus subtilis (natto) [106]. It has fibrinolytic activity when administered orally and is widely available in processed and health foods containing natto (fermented soybean) extracts. Besides its potent fibrinolytic activity, enhancing plasminogen activators and inactivating a plasminogen activator inhibitor, Nattokinase also hydrolyzes collagen fibers [107, 108]. Based on this propriety, Takano and associates [86] investigated the liquefying efficacy when injected into the vitreous cavity. Different doses of nattokinase $(1,0.1$, or 0.01 fibrindegradation units (FU)) were injected into the vitreous of rabbits. Scanning electron microscopy showed smooth retinal surfaces, indicating the occurrence of PVD at 30 minutes after intervention in all the experimental eyes injected with 0.1 or 1.0 FU nattokinase. However, with the higher dose (1 FU) of nattokinase toxicity in the form of preretinal hemorrhage and ERG changes was noted. Further study of the optimal concentration of nattokinase and the mechanism of its adverse effects should be conducted.

\section{d) Chondroitinase (Chondroitin ABC Lyase)}

Chondroitinase is an enzyme which degrades chondroitin sulphate. Bishop and colleagues [87] studied the mode of action chondroitin ABC-lyase in bovine vitreous gel and found it similar to hyaluronidase. They reported a depolymerization of hyaluronan as well as the CS without destroying the vitreous structure, resulting in a slight reduction in the gel wet weight. In porcine cadaver eyes, chondroitinase also proved to facilitate vitreous mass removal after 1-3 hour of incubation [109]. In vivo, however, Hermel and Schrage [110] could not demonstrate an enhanced frequency of PVD after 60 minutes of treatment with 1 IU chondroitinase in the pig. This is probably because the dose was too low. Indeed, experiments in monkeys were performed using higher doses $(20-10.000 \mathrm{IU})$ and proved the efficacy of this enzyme in separating vitreous from retina without damaging the ILL, just 5 to 15 minutes after injection. Chondroitinase has also been utilized to detach epiretinal membranes in four monkeys, without evidence of toxicity [72]. Further investigations into the mode of action and efficacy of chondroitinase are necessary to establish its possible role as an aid to vitrectomy. On theoretical grounds, this agent is very attractive since it is both a liquefactant and interfactant.

\section{e) Plasmin}

Plasmin is a non-specific serine protease mediating the fibrinolytic process, and acting on a variety of glycoproteins including laminin and fibronectin, which are present between vitreous the collagen fibrils of the posterior vitreous cortex and the internal limiting lamina at the retina [14, 33]. In a landmark paper published in 1993, Verstraeten and colleagues induced PVD in rabbit eyes by intravitreal injection of this enzyme followed by vitrectomy [82]. In 1999, Hikichi and co-workers [95] confirmed complete PVD after injection of $1 \mathrm{U}$ plasmin and $0.5 \mathrm{ml} \mathrm{SF}_{6}$ gas in the rabbit model, without evidence of retinal toxicity. In an electron microscopic study, the vitreoretinal interface in postmortem human eyes showed complete vitreous separation with sparse collagen fibrils after the injection of plasmin [111]. There are various approaches to obtaining plasmin for clinical use (Fig. (6)).

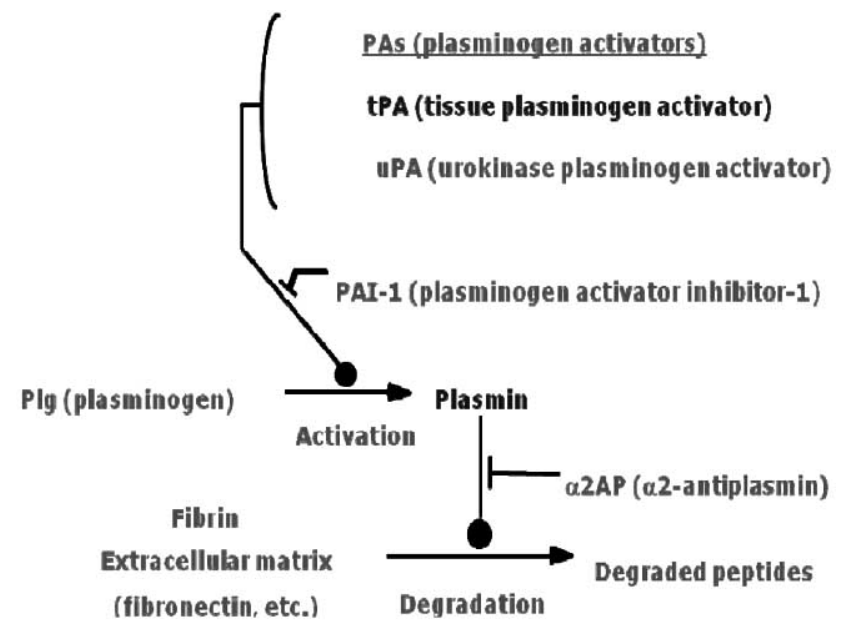

Fig. (6). Plasminogen system. As an enzyme, tPA catalyses the conversion of plasminogen to plasmin and mediating the degradation of extracellular matrix proteins.

\section{- Tissue plasminogen activator (tPA)}

tPA is a serine protease found on endothelial cells that is responsible for catalyzing the conversion of plasminogen to plasmin, the major enzyme responsible for clot breakdown 
[112]. Because it works as fibrinolytic agent, tPA is used to treat embolic or thrombolytic stroke [113]. tPA has also been injected into vitreous in an attempt to generate plasmin by activation of endogenous plasminogen [114]. However, in order to allow plasminogen to enter the vitreous, a breakdown of the blood-retinal-barrier (BRB) proved to be necessary.

Hesse et al. [114] were the first report success in using intravitreal injection of tPA to induce PVD. Several other studies $[95,97,115]$ have since described the mechanism of PVD induction by tPA, in particular plasmin activation increasing the degradation of extracellular matrix proteins. In the rabbit, a complete PVD was observed in all eyes treated with $25 \mu \mathrm{g} \mathrm{tPA}$. Case series and retrospective studies also observed PVD after intravitreal injection of tPA [116, 117]. Although, PVD was carefully confirmed by the OCT findings and the observation Weiss's (glial) ring, this might not be sufficient to determine the presence of PVD. Furthermore, a prospective, randomized, double-blind study designed by Le Mer et al. in patients with PDVR did not suggest benefit in the 25ug tPA treatment group [118]. They divided 56 patients undergoing surgery for complications of DR into two groups: one receiving 25ug tPA 15 minutes before vitrectomy and the other receiving just buffered salt solution (BSS). The major criteria for comparison were the number of perioperative iatrogenic tears, the gain in visual acuity, and the reattachment rate of tractional retinal detachments. The authors attributed the failure of tPA to the short delay between TPA injection and beginning of surgery, an insufficient dose, or an insufficient quantity of plasminogen in the vitreous at the beginning of the intervention.

Nonetheless, tPA has a role in vitreoretinal surgery as adjuvant therapy for the treatment of postvitrectomy fibrin formation and submacular hemorrhage. Another therapeutic effect of intravitreal tPA was described by Chung et al. [119] in diabetic patients with massive premacular hemorrhage. It is likely that these patients have blood into a vitreoschisis cavity. A Nd:YAG laser membranotomy was performed on the anterior was of the vitreoschisis cavity and tPA (25 microg/ $0.1 \mathrm{~mL}$ ) was injected into the vitreous cavity of seven eyes, along with $0.2 \mathrm{~mL}$. After the combined therapy, the patients recovered vision within 4 weeks and the hemorrhages were completely absorbed within 8 weeks. There were no associated ophthalmic complications.

\section{- Autologous Plasmin Enzyme (APE)}

APE is generally obtained by a long and expensive procedure that requires the collaboration of a blood unit. First, the plasminogen is isolated from human plasma by affinity chromatography. Then it is concentrated and activated by the addition of streptokinase. Finally, it is sterilized by filtration. Although the use of plasmin obtained by chromatography has been found to be safe and efficient, the production of the plasmin enzyme is technically and logistically difficult and expensive. Hence, other alternative method has been proposed to facilitate the production of the APE for vitreoretinal surgery; 1 hour before surgery a sample of the patient's blood is centrifuged and incubated with streptokinase [120]. Using this method, Rizzo and coauthors reported the presence of PVD in $85 \%$ of the eyes which received the APE solution intravitreally [120].
Pharmacologic vitreolysis by intravitreal injection of APE has been proposed by several researchers. In a pilot study, Williams et al. [71] assessed the use of the APE as an adjuvant to vitreous surgery in eyes with advanced diabetic retinopathy. A beneficial surgical result was also reported in cases of pediatric macular $[98,121]$ and idiopathic macular holes in adults [122]. There is evidence of a favorable effect of plasmin on the ultrastructure of the ILL and its separation from the vitreous, as reported by Asami et al. [97]. However, the efficacy and toxicity of intravitreal APE is dosedependent. Intravitreal injection of $0.4 \mathrm{IU}$ of plasmin has been demonstrated to be sufficient to separate the posterior vitreous cortex from the ILL, without resulting in retinal toxicity, up to the maximal tested concentration of 3-4 $\mathrm{IU} / \mathrm{mL}$. Gandorfer and colleagues [123] also found a direct correlation between the exposure time of plasmin and the degree of vitreoretinal separation in pigs' eyes. They achieved a complete vitreous detachment in eyes exposed to $2 \mathrm{IU}$ plasmin for $60 \mathrm{~min}$.

Recently, Diaz-Llopis et al. [124] evaluated the efficacy of an intravitreal injection of $0.2 \mathrm{ml}$ of APE without a vitrectomy to treat refractory diffuse diabetic macular edema. Sixteen patients with bilateral DME who had not responded to prior laser photocoagulation, received an injection in one eye, while the fellow eye served as a control. Intravitreal APE injection effectively reduced macular thickening and improved visual acuity in a 1-month follow-up. Further prospective and randomized studies with a more representative number of patients are needed to determine more accurately which patients could benefit most from this treatment, and how often and at what concentration the autologous plasmin should be administered.

\section{- Microplasmin}

Microplasmin is a recombinant protein, representing the truncated form of the human plasmin with retained protease activity [84]. The molecular weight of microplasmin is 28 $\mathrm{kDa}$, which is lower than the molecular weight of human plasmin $(88 \mathrm{kDa})$. Theoretically, this should enable microplasmin to penetrate epiretinal tissue more effectively than plasmin. Tests conducted in pig, cat, and human eyes have confirmed that it can produce posterior vitreous separation, leaving a smooth retinal surface at doses of approximately 125 ug [84, 115, 125]. Histologic and ERG analyses, in rabbit's eyes revealed no evidence of toxicity $[82,115]$ except for a transient decrease in a- and b-wave amplitudes which was seen in eyes that received higher doses of microplasmin even 90 days after injection. In another study, only increasing doses from $0.01 \mathrm{U}$ to $0.03 \mathrm{U}$ injected into rats eyes to induce PVD showed degradation of photoreceptors and the outer retina [126].

Microplasmin (ThromboGenics, Leuven, Belgium) activity and safety was also evaluated in human patients. The MIVI trial [127], was a prospective uncontrolled and nonrandomized trial to investigate the effect of 4 doses $(25,50$, 75 or $125 \mathrm{ug}$ in $100 \mathrm{uL}$ ) of microplasmin given $1 \mathrm{~h}, 1$ day, and 1 week before vitrectomy in patients with vitreomacular traction. Even at the lower doses, with increasing time, a higher proportion of patients achieved posterior vitreous detachment. Only one retinal detachment developed shortly after administration of microplasmin and two developed after 
surgery, confirming the safety of this approach. It was noted at surgery that with a $125 \mathrm{ug}$ dose, patients had a discontinuous layer of vitreous present on the retinal surface resulting from the induction of a PVD and vitreoschisis.

Even more recently a phase 2, multicenter, placebocontrolled, double-masked, parallel-group, dose-ranging clinical MIVI trial [70] evaluated the safety and efficacy of a preoperative intravitreous injection of microplasmin in 125 patients scheduled for vitreous surgery for either vitreomacular traction or macular hole. Intravitreous injection of either microplasmin at 1 of 3 doses $(25 \mathrm{ug}, 75 \mathrm{ug}$, or $125 \mathrm{ug}$ ) or placebo was administered 7 days before PPV. Rates of total PVD at the time of surgery were $10 \%, 14 \%, 18 \%$, and $31 \%$ in the placebo group, $25 \mathrm{ug}, 75 \mathrm{ug}$ and $125 \mathrm{ug}$ microplasmin groups, respectively. In terms of resolution of vitreomacular interface abnormality precluding the need for vitrectomy at the 35 -day was observed at rates of $3 \%, 10 \%, 15 \%$, and $31 \%$ in the placebo, and the $25 \mathrm{ug}$, the $75 \mathrm{ug}$ and the $125 \mathrm{ug} \mathrm{mi}-$ croplasmin groups, respectively. At the 180-day time point, the equivalent rates were $3 \%, 7 \%, 15 \%$, and $28 \%$, respectively. Resolution of anomalous PVD may also be associated with this result. Thus microplasmin is currently the most promising approach to treat vitreoretinal traction by pharmacologic vitreolysis.

\section{f) Dispase}

Dispase, also called neutral protease, has the capability to hydrolyze several proteins including collagen type IV and fibronectin, which are present at the vitreoretinal interface and support attachment of the vitreous cortex to the ILl [77, 138]. Application of dispase in porcine eyes induced a PVD $[76,77]$. However, dispase appeared to be toxic to the retina at the different doses and time courses. Intravitreal dispase caused substantial damage including preretinal hemorrhage and vitreous inflammation after 15 minutes. Longer exposure ( 7 days) to a higher dose of dispase $(0.1 \mathrm{U})$ can induce $n$. irreversible cataract, as well as ERM formation [78]. Because dispase derives usually from Bacillus polymyxa, containing endotoxin, it may not be optimal for intraocular application.

\subsubsection{Non-Enzymatic Agents}

\section{a) RGD-Peptides}

RGD-peptides administered into the vitreous cavity might also weaken vitreoretinal adhesion by a non-enzymatic mechanism of action. The extracellular matrix (ECM) proteins at the RGD-containing binding side cross-compete with RGD-peptides applied to the vitreous [129]. As previously explained, the ILL is predominantly composed by proteins including fibronectin, laminin and collagen types I and IV. These ECM components are critical in the mediation of cellcell and cell-matrix interactions such as vitreomacular adhesion. Adhesions and signals of the ECM are normally transmitted to cellular tissue via receptors on the cell surface, called integrins. The primary connection of these integrins to the ECM involves the Arg-Gly-Asp (RGD) binding sequences. The integrins are heavily linked to fibronectin and laminin at this cellular side, which are the major adhesive glycoproteins of the ILM in the eye especially in DR. Several integrins bind through the RGD binding site with other
ECM proteins, such as fibronectin, vitronectin, laminin and collagen. Most importantly, the analogs of synthetic peptides of RGD such as Gly-Arg-Asp-Thr-Pro (GRGDTP) are known to compete for the RGD motif of ECM proteins to disrupt integrin-ECM-interactions and therefore loosen the attachments. Evidence suggests that these adhesions are defined, at least in part, by collagen fibrils of the cortical vitreous anchored in the ILM adjacent to Müller cell pedicles on the inner surface of the retina [129]. Previous research in pharmacologic vitreolysis has concentrated on using enzymes to promote digestion of the ECM, consequently producing a non-specific destruction of adjacent tissue and sometimes unwanted side effects.

\section{b) Vitreosolve ${ }^{\circledR}$}

Vitreosolve ${ }^{\circledR}$ is another non-enzymatic agent for pharmacologic vitreolysis that has been evaluated in Phase III clinical trials conducted at multiple sites in the United States, India, and Mexico. This agent is comprise of urea which 'unravels' collagen fibers and purportedly induces both liquefaction and vitreo-retinal dehiscence, making it both a liquefactant and interfactant. The objective of these clinical trials was to evaluate the safety and efficacy of intravitreal injections of Vitreosolve ${ }^{\circledR}$ to induce a PVD (as determined by ultrasound) in patients with non-proliferative diabetic retinopathy (NPDR). This prospective, randomized, doublemasked, placebo-controlled study enrolled approximately 400 patients with NPDR in the United States and India, and 150 in Mexico. The study design involved monthly intravitreal injections for 3 months. The results showed that while Vitreosolve ${ }^{\circledR}$ did induce a PVD in $50 \%$ of cases, PVD also occurred in $36 \%$ of controls (V. Karageozian, MD personal communication). This difference was not statistically significant and all clinical research with Vitreosolve ${ }^{\circledR}$ has been terminated.

While this is disappointing, there may be valuable lessons to be learned. It is important that clinical trials be designed with sufficiently large subject groups to assure statistically-significant results. Thus, while the Vitreosolve ${ }^{\circledR}$ trials involved over 500 subjects, these were apparently not sufficiently large numbers. Secondly, no pre-clinical studies were done with Vitreosolve ${ }^{\circledR}$ in diabetic animals or patients. Studies have previously shown that the vitreous gel and vitreoretinal interface in diabetic patients is quite different from normals [29, 31, 32]. Thus, investigators are well-advised to research the effects of agents for pharmacologic vitreolysis in appropriate models of the ultimate disease application [90], in this case to induce PVD in subjects with diabetic vitreopathy [29, 31, 32] and vitreo-retinopathy [42]. This shortcoming was also a factor in the failure of Vitrase ${ }^{\circledR}$ (a hyaluronidase) to induce beneficial effects in diabetic patients. That pharmacologic vitreolysis liquefactant also failed to obtain FDA approval for pharmacologic vitreolysis and is also not currently in clinical use.

\section{FUTURE PERSPECTIVES}

It has long been known that vitrectomy surgery can aid in the treatment of diabetic retinopathy [130]. This phenomenon has been hypothesized to be linked with a PVD-induced relief of hypoxia in ischemic regions of the diabetic inner retina as a result of increased movement of $\mathrm{O}_{2}$ from $\mathrm{O}_{2}$-rich 
to $\mathrm{O}_{2}$-poor areas of the vitreoretinal surface $[50,131,132]$. Barbazetto et al. [133] recently demonstrated an increase in $\mathrm{pO}_{2}$ levels in the vitreous following vitrectomy surgery in humans. Thus, achieving a clean enzymatic separation between the ILL of the retina and the posterior vitreous cortex by pharmacologic means could be an effective treatment for ischemic retinal diseases by increasing vitreo-retinal $\mathrm{O}_{2}$ exchange. It has been shown that PVD formation leads to elevated levels of $\mathrm{O}_{2}$ in the lens nucleus. This finding may have implication with regard to the occurrence of age-related PVD in the human and a possible acceleration of maturity-onset nuclear cataract. In addition, the demonstration that an enzymatic creation of a PVD significantly increased the rate of $\mathrm{O}_{2}$ exchange within the vitreous may have potential application for treatment of retinal ischemic disease. The ability of several agents to induce a PVD and increase $\mathrm{O}_{2}$ exchange in vitreous may have clinical applications regarding treatment of retinal ischemia.

In the future, pharmacologic vitreolysis research should be performed on eyes with abnormal vitreous, see conditions identified in (Fig. 4) as well as systemic condition such as diabetes [90]. It is known, for example, that diabetes induces significant biochemical and structural effects on vitreous, resulting in diabetic vitreopathy [31]. The diabetic vitreous is so significantly different from normal vitreous, studies on the effects of pharmacologic vitreolysis on normal vitreous may fail to result in effective implementation of this therapy in pathologic conditions. This consideration might partly explain why hyaluronidase failed in Phase III FDA clinical trials for treating vitreous hemorrhage in diabetic retinopathy [74]. Although this agent did clear vitreous hemorrhage in $32.9 \%$ of cases, the saline control also cleared the blood in $25.5 \%$ of cases [39]: Another explanation for the failure of Vitrase relates to the fact that hyaluronidase is not an interfactant, only a liquefactant (Table 1). Thus, although hyaluronidase will liquefy gel vitreous, it will not induce vitreoretinal dehiscence.

The recent studies findings with microplasmin (125 ug dose [127]), tPA and APE hold promise for inducing PVD without morphologic alteration of the retina. This approach, is effective in approximately $30 \%$ of cases reducing the need for surgery. It is possible, that more than one agent may be needed simultaneously to increase the efficacy rates [11]. Future research should explore this approach as well as investigate new and more potent agents for innocuous pharmacologic vitreolysis. This will be necessary before pharmacologic vitreolysis can be used as prophylaxis for advanced diabetic vitreo-retinopathy on a widespread basis.

\section{REFERENCES}

[1] Sebag, J. Macromolecular structure of vitreous. Prog. Polym. Sci., 1998, 23(1), 415-446.

[2] Bishop, P. N. Structural macromolecules and supramolecular organisation of the vitreous gel. Prog. Retin. Eye Res., 2000, 19(3), 323-344.

[3] Lee, B.; Litt, M.; Buchsbaum, G. Rheology of the vitreous body. Part I: Viscoelasticity of human vitreous. Biorheology, 1992, 29, (5-6), 521-533.

[4] Sebag, J. The Vitreous: Structure, Function, and Pathobiology; Springer-Verlag: New York, 1989.

[5] Meyer, K.; Palmer, J. W. The polyssacharide of the vitreous humour. J. Biol. Chem., 1934, 107, 629-634.
[6] Bishop, P. The biochemical structure of mammalian vitreous. Eye, (Lond) 1996, 10(Pt 6), 664-670.

[7] Brewton, R. G.; Mayne, R. Mammalian vitreous humor contains networks of hyaluronan molecules: electron microscopic analysis using the hyaluronan-binding region (G1) of aggrecan and link protein. Exp. Cell Res., 1992, 198(2), 237-249.

[8] Schwartz, S. D.; Alexander, R.; Hiscott, P.; Gregor, Z. J. Recognition of vitreoschisis in proliferative diabetic retinopathy. A useful landmark in vitrectomy for diabetic traction retinal detachment. Ophthalmology, 1996, 103(2), 323-328.

[9] Bishop, P. N.; Crossman, M. V.; McLeod, D.; Ayad, S. Extraction and characterization of the tissue forms of collagen types II and IX from bovine vitreous. Biochem. J., 1994, 299(Pt 2), 497-505.

[10] Ramesh, S.; Bonshek, R. E.; Bishop, P. N. Immunolocalisation of opticin in the human eye. Br. J. Ophthalmol., 2004, 88(5), 697-702.

[11] Sebag, J. Is pharmacologic vitreolysis brewing? Retina, 2002, 22(1), 1-3.

[12] Matsumoto, B.; Blanks, J. C.; Ryan, S. J. Topographic variations in the rabbit and primate internal limiting membrane. Invest. Ophthalmol. Vis. Sci., 1984, 25(1), 71-82.

[13] Li, X.; Shi, X.; Fan, J. Posterior vitreous detachment with plasmin in the isolated human eye. Graefes Arch. Clin. Exp. Ophthalmol., 2002, 240(1), 56-62.

[14] Kohno, T.; Sorgente, N.; Patterson, R.; Ryan, S. J. Fibronectin and laminin distribution in bovine eye. Jpn. J. Ophthalmol., 1983, 27(3), 496-505.

[15] Stenman, S.; Vaheri, A. Distribution of a major connective tissue protein, fibronectin, in normal human tissues. J. Exp. Med., 1978, 147(4), 1054-1064.

[16] Engvall, E.; Ruoslahti, E.; Miller, E. J. Affinity of fibronectin to collagens of different genetic types and to fibrinogen. J. Exp. Med., 1978, 147(6), 1584-1595.

[17] Terranova, V. P.; Rohrbach, D. H.; Martin, G. R. Role of laminin in the attachment of PAM 212(epithelial) cells to basement membrane collagen. Cell, 1980, 22(3), 719-726.

[18] Terranova, V. P.; Liotta, L. A.; Russo, R. G.; Martin, G. R. Role of laminin in the attachment and metastasis of murine tumor cells. Cancer Res., 1982, 42(6), 2265-2269.

[19] Yurchenco, P. D.; Schittny, J. C. Molecular architecture of basement membranes. FASEB J., 1990, 4(6), 1577-1590.

[20] Inoue, S.; Leblond, C. P.; Rico, P.; Grant, D. Association of fibronectin with the microfibrils of connective tissue. Am. J. Anat., 1989, 186(1), 43-54.

[21] Sebag, J. Age-related differences in the human vitreoretinal interface. Arch. Ophthalmol., 1991, 109(7), 966-971.

[22] Foos, R. Y.; Wheeler, N. C. Vitreoretinal juncture. Synchysis senilis and posterior vitreous detachment. Ophthalmology, 1982 89(12), 1502-1512.

[23] Sebag, J. Age-related changes in human vitreous structure. Graefes Arch. Clin. Exp. Ophthalmol., 1987, 225(2), 89-93.

[24] Sebag, J. Anomalous posterior vitreous detachment: a unifying concept in vitreo-retinal disease. Graefes Arch. Clin. Exp. Ophthalmol., 2004, 242(8), 690-698.

[25] Faulborn, J.; Bowald, S. Microproliferations in proliferative diabetic retinopathy and their relationship to the vitreous: corresponding light and electron microscopic studies. Graefes Arch. Clin. Exp. Ophthalmol., 1985, 223(3), 130-138.

[26] Hammes, H. P.; Lin, J.; Bretzel, R. G.; Brownlee, M.; Breier, G. Upregulation of the vascular endothelial growth factor/vascular endothelial growth factor receptor system in experimental background diabetic retinopathy of the rat. Diabetes, 1998, 47(3), 401406.

[27] Hammes, H. P.; Wellensiek, B.; Kloting, I.; Sickel, E.; Bretzel, R. G.; Brownlee, M. The relationship of glycaemic level to advanced glycation end-product (AGE) accumulation and retinal pathology in the spontaneous diabetic hamster. Diabetologia, 1998, 41(2), $165-170$

[28] Malecaze, F.; Clamens, S.; Simorre-Pinatel, V.; Mathis, A. Chollet, P.; Favard, C.; Bayard, F.; Plouet, J. Detection of vascular endothelial growth factor messenger RNA and vascular endothelial growth factor-like activity in proliferative diabetic retinopathy. Arch. Ophthalmol., 1994, 112(11), 1476-1182.

[29] Sebag, J.; Buckingham, B.; Charles, M. A.; Reiser, K. Biochemical abnormalities in vitreous of humans with proliferative diabetic retinopathy. Arch. Ophthalmol., 1992, 110(10), 1472-1476. 
[30] Hendrikse, F.; Yeo, K. T. Role of the vitreous body in diabetic retinopathy. Klin. Monbl. Augenheilkd., 1993, 203(5), 319-323.

[31] Sebag, J. Diabetic vitreopathy. Ophthalmology, 1996, 103(2), 205206.

[32] Sebag, J.; Nie, S.; Reiser, K.; Charles, M. A.; Yu, N. T. Raman spectroscopy of human vitreous in proliferative diabetic retinopathy. Invest. Ophthalmol. Vis. Sci., 1994, 35(7), 2976-2980.

[33] Kohno, T.; Sorgente, N.; Ishibashi, T.; Goodnight, R.; Ryan, S. J. Immunofluorescent studies of fibronectin and laminin in the human eye. Invest. Ophthalmol. Vis. Sci., 1987, 28(3), 506-514.

[34] Sebag, J. Vitreoschisis. Graefes Arch. Clin. Exp. Ophthalmol., 2008, 246(3), 329-332.

[35] Chu, T. G.; Lopez, P. F.; Cano, M. R.; Freeman, W. R.; Lean, J. S.; Liggett, P. E.; Thomas, E. L.; Green, R. L. Posterior vitreoschisis. An echographic finding in proliferative diabetic retinopathy. Ophthalmology, 1996, 103(2), 315-322.

[36] Sebag, J.; Buzney, S. M.; Belyea, D. A.; Kado, M.; McMeel, J. W.; Trempe, C. L. Posterior vitreous detachment following panretinal laser photocoagulation. Graefes Arch. Clin. Exp. Ophthalmol., 1990, 228(1), 5-8.

[37] Casaroli Marano, R. P.; Preissner, K. T.; Vilaro, S. Fibronectin, laminin, vitronectin and their receptors at newly-formed capillaries in proliferative diabetic retinopathy. Exp. Eye Res., 1995, 60(1), 517.

[38] Akiba, J.; Ueno, N.; Chakrabarti, B. Molecular mechanisms of posterior vitreous detachment. Graefes Arch. Clin. Exp. Ophthalmol., 1993, 231(7), 408-412.

[39] Hesse, L.; Bodanowitz, S.; Huhnermann, M.; Kroll, P. Prediction of visual acuity after early vitrectomy in diabetics. Ger. J. Ophthalmol., 1996, 5(5), 257-261.

[40] Shea, M. Early vitrectomy in proliferative diabetic retinopathy. Arch. Ophthalmol., 1983, 101(8), 1204-1205.

[41] Kroll, P.; Meyer-Rusenberg, H. W.; Busse, H. Recommendation for staging of proliferative diabetic retinopathy. Fortschr. Ophthalmol., 1987, 84(4), 360-363.

[42] Kroll, P.; Rodrigues, E. B.; Hoerle, S. Pathogenesis and classification of proliferative diabetic vitreoretinopathy. Ophthalmologica, 2007, 221(2), 78-94.

[43] Kroll, P.; Meyer-Rusenberg, H. W.; Berg, P. Does vitrectomy in proliferative diabetic retinopathy effect an improvement in intraocular metabolic status? Fortschr. Ophthalmol., 1986, 83(4), 471-473.

[44] Wang, M. Y.; Nguyen, D.; Hindoyan, N.; Sadun, A. A.; Sebag, J. Vitreo-papillary adhesion in macular hole and macular pucker. Retina, 2009, 29(5), 644-650.

[45] Kroll, P.; Wiegand, W.; Schmidt, J. Vitreopapillary traction in proliferative diabetic vitreoretinopathy [see comments]. $\mathrm{Br}$. J. Ophthalmol., 1999, 83(3), 261-264.

[46] Karatas, M.; Ramirez, J. A.; Ophir, A. Diabetic vitreopapillary traction and macular oedema. Eye, (Lond) 2005, 19(6), 676-682.

[47] Katz, B.; Hoyt, W. F. Gaze-evoked amaurosis from vitreopapillary traction. Am. J. Ophthalmol., 2005, 139(4), 631-637.

[48] Kroll, P.; Wiegand, W.; Schmidt, J. Traction vitreoretinal opticopathy in proliferative diabetic vitreoretinopathy. Ophthalmologe, 1995, 92(5), 687-691.

[49] Stefansson, E. The therapeutic effects of retinal laser treatment and vitrectomy. A theory based on oxygen and vascular physiology. Acta Ophthalmol. Scand., 2001, 79(5), 435-440.

[50] Stefansson, E.; Landers, M. B. 3rd, How does vitrectomy affect diabetic macular edema? Am. J. Ophthalmol., 2006, 141(5), 984985.

[51] Grewing, R.; Mester, U. Early vitrectomy for progressive diabetic proliferations covering the macula. Br. J. Ophthalmol., 1994, 78(6), 433-436.

[52] Nasrallah, F. P.; Jalkh, A. E.; Van Coppenolle, F.; Kado, M.; Trempe, C. L.; McMeel, J. W.; Schepens, C. L. The role of the vitreous in diabetic macular edema. Ophthalmology, 1988, 95, (10), 1335-1339.

[53] Sebag, J.; Gupta, P.; Rosen, R. R.; Garcia, P.; Sadun, A. A. Macular holes and macular pucker: the role of vitreoschisis as imaged by optical coherence tomography/scanning laser ophthalmoscopy. Trans. Am. Ophthalmol. Soc., 2007, 105, 121-129.

[54] Hikichi, T.; Fujio, N.; Akiba, J.; Azuma, Y.; Takahashi, M.; Yoshida, A. Association between the short-term natural history of diabetic macular edema and the vitreomacular relationship in type II diabetes mellitus. Ophthalmology, 1997, 104(3), 473-478.
[55] Pendergast, S. D.; Hassan, T. S.; Williams, G. A.; Cox, M. S.; Margherio, R. R.; Ferrone, P. J.; Garretson, B. R.; Trese, M. T. Vitrectomy for diffuse diabetic macular edema associated with a taut premacular posterior hyaloid. Am. J. Ophthalmol., 2000, $130(2), 178-186$

[56] Lewis, H.; Abrams, G. W.; Blumenkranz, M. S.; Campo, R. V. Vitrectomy for diabetic macular traction and edema associated with posterior hyaloidal traction. Ophthalmology, 1992, 99, (5), 753759.

[57] Sebag, J. Anatomy and pathology of the vitreo-retinal interface. Eye, (Lond) 1992, 6(Pt 6), 541-552.

[58] Sebag, J.; Balazs, E. A. Pathogenesis of cystoid macular edema: an anatomic consideration of vitreoretinal adhesions. Surv. Ophthalmol., 1984, 28(Suppl), 493-498.

[59] Newton, I. Philosophiæ naturalis principia mathematica. 1726.

[60] Stefansson, E.; Landers, M. B. 3rd; Wolbarsht, M. L. Increased retinal oxygen supply following pan-retinal photocoagulation and vitrectomy and lensectomy. Trans. Am. Ophthalmol. Soc., 1981, 79, 307-334.

[61] Stefansson, E.; Landers, M. B. $3^{\text {rd }}$. Wolbarsht, M. L. Vitrectomy, lensectomy, and ocular oxygenation. Retina, 1982, 2(3), 159-166.

[62] Laidlaw, D. A. Vitrectomy for diabetic macular oedema. Eye, (Lond) 2008, 22, (10), 1337-1341

[63] Yamamoto, T.; Takeuchi, S.; Sato, Y.; Yamashita, H. Long-term follow-up results of pars plana vitrectomy for diabetic macular edema. Jpn. J. Ophthalmol., 2007, 51(4), 285-291.

[64] DRCRnet. Vitrectomy outcomes in eyes with diabetic macular edema and vitreomacular traction. Ophthalmology, 2010, 117(6), 1087-1093.

[65] Pirie, A. Ox vitreous humour; hyaluronic acid relationships. $B r . J$. Ophthalmol., 1949, 33(5), 271-283.

[66] O'Neill, R.; Shea, M. The effects of bacterial collagenase in rabbit vitreous. Can. J. Ophthalmol., 1973, 8(2), 366-370.

[67] Sebag, J. Pharmacologic vitreolysis. Retina, 1998, 18(1), 1-3.

[68] Bhisitkul, R. B. Anticipation for enzymatic vitreolysis. Br. J. Ophthalmol., 2001, 85, 1-2.

[69] Gandorfer, A. Pharmacologic vitreolysis. Dev. Ophthalmol., 2007, 39, 149-156.

[70] Benz, M. S.; Packo, K. H.; Gonzalez, V.; Pakola, S.; Bezner, D Haller, J. A.; Schwartz, S. D. A placebo-controlled trial of microplasmin intravitreous injection to facilitate posterior vitreous detachment before vitrectomy. Ophthalmology, 2010, 117(4), 791797.

[71] Williams, J. G.; Trese, M. T.; Williams, G. A.; Hartzer, M. K. Autologous plasmin enzyme in the surgical management of diabetic retinopathy. Ophthalmology, 2001, 108(10), 1902-1905.

[72] Hageman, G. S.; Russell, S. R. Chondroitinase-mediated disinsertion of the primate vitreous body. Invest. Ophthalmol. Vis. Sci. 1994, 35(4), 1260.

[73] Kuppermann, B. D.; Thomas, E. L.; de Smet, M. D.; Grillone, L. R. Pooled efficacy results from two multinational randomized controlled clinical trials of a single intravitreous injection of highly purified ovine hyaluronidase (Vitrase) for the management of vitreous hemorrhage. Am. J. Ophthalmol., 2005, 140(4), 573-584.

[74] Kuppermann, B. D.; Thomas, E. L.; de Smet, M. D.; Grillone, L. R. Safety results of two phase III trials of an intravitreous injection of highly purified ovine hyaluronidase (Vitrase) for the management of vitreous hemorrhage. Am. J. Ophthalmol., 2005, 140(4), 585597.

[75] Hikichi, T.; Kado, M.; Yoshida, A. Intravitreal injection of hyaluronidase cannot induce posterior vitreous detachment in the rabbit. Retina, 2000, 20(2), 195-198.

[76] Tezel, T. H.; Del Priore, L. V.; Kaplan, H. J. Posterior vitreous detachment with dispase. Retina, 1998, 18(1), 7-15.

[77] Oliveira, L. B.; Tatebayashi, M.; Mahmoud, T. H.; Blackmon, S. M.; Wong, F.; McCuen, B. W. 2nd, Dispase facilitates posterior vitreous detachment during vitrectomy in young pigs. Retina, 2001, 21(4), 324-331.

[78] Jorge, R.; Oyamaguchi, E. K.; Cardillo, J. A.; Gobbi, A.; Laicine, E. M.; Haddad, A. Intravitreal injection of dispase causes retinal hemorrhages in rabbit and human eyes. Curr. Eye Res., 2003 , 26(2), 107-112.

[79] Lariukhina, G. M.; Ziangirova, G. G. Experimental enzymatic vitreolysis. Vestn. Oftalmol., 1977, (6), 77-79. 
[80] Zagorski, Z. Effect of enzymatic vitreolysis on the absorption of experimental vitreous hemorrhage. Preliminary report. Klin. Oczna., 1983, 85(5), 197-199.

[81] Hesse, L.; Nebeling, B.; Schroeder, B.; Heller, G.; Kroll, P. Induction of posterior vitreous detachment in rabbits by intravitreal injection of tissue plasminogen activator following cryopexy. Exp. Eye Res., 2000, 70(1), 31-39.

[82] Verstraeten, T. C.; Chapman, C.; Hartzer, M.; Winkler, B. S.; Trese, M. T.; Williams, G. A. Pharmacologic induction of posterior vitreous detachment in the rabbit. Arch. Ophthalmol., 1993, 111(6), 849-854.

[83] Uemura, A.; Nakamura, M.; Kachi, S.; Nishizawa, Y.; Asami, T.; Miyake, Y.; Terasaki, H. Effect of plasmin on laminin and fibronectin during plasmin-assisted vitrectomy. Arch. Ophthalmol., 2005, 123(2), 209-213.

[84] Sakuma, T.; Tanaka, M.; Mizota, A.; Inoue, J.; Pakola, S. Safety of in vivo pharmacologic vitreolysis with recombinant microplasmin in rabbit eyes. Invest. Ophthalmol. Vis. Sci., 2005, 46(9), 32953299.

[85] Sebag, J.; Ansari, R. R.; Suh, K. I. Pharmacologic vitreolysis with microplasmin increases vitreous diffusion coefficients. Graefes Arch. Clin. Exp. Ophthalmol., 2007, 245(4), 576-580.

[86] Takano, A.; Hirata, A.; Ogasawara, K.; Sagara, N.; Inomata, Y.; Kawaji, T.; Tanihara, H. Posterior vitreous detachment induced by nattokinase (subtilisin NAT): a novel enzyme for pharmacologic vitreolysis. Invest. Ophthalmol. Vis. Sci., 2006, 47(5), 2075-2079.

[87] Bishop, P. N.; McLeod, D.; Reardon, A. Effects of hyaluronan lyase, hyaluronidase, and chondroitin ABC lyase on mammalian vitreous gel. Invest. Ophthalmol. Vis. Sci., 1999, 40(10), 21732178.

[88] Wang, F.; Wang, Z.; Sun, X.; Wang, F.; Xu, X.; Zhang, X. Safety and efficacy of dispase and plasmin in pharmacologic vitreolysis. Invest Ophthalmol. Vis. Sci., 2004, 45(9), 3286-3290

[89] Wang, Z. L.; Zhang, X.; Xu, X.; Sun, X. D.; Wang, F. PVD following plasmin but not hyaluronidase: implications for combination pharmacologic vitreolysis therapy. Retina, 2005, 25(1), 38-43.

[90] Sebag, J. Pharmacologic vitreolysis--premise and promise of the first decade. Retina, 2009, 29(7), 871-874.

[91] Sikri, N.; Bardia, A. A history of streptokinase use in acute myocardial infarction. Tex. Heart Inst. J., 2007, 34(3), 318-327.

[92] Meneveau, N.; Schiele, F.; Vuillemenot, A.; Valette, B.; Grollier, G.; Bernard, Y.; Bassand, J. P. Streptokinase vs alteplase in massive pulmonary embolism. A randomized trial assessing right heart haemodynamics and pulmonary vascular obstruction. Eur. Heart J., 1997, 18(7), 1141-1148.

[93] Cherfan, G. M.; el Maghraby, A.; Tabbara, K. F.; Nasr, Y.; Hassan, H. Dissolution of intraocular fibrinous exudate by streptokinase. Ophthalmology, 1991, 98(6), 870-874.

[94] El Baha, S. M.; Abou-Nazel, M. W.; Idriss, H. F.; Abdel-Megeed, A. S. The role of streptokinase in induction of posterior vitreous detachment: a scanning and transmission electron microscopic study of the retina in rabbits. Retina, 2003, 23(5), 698-704.

[95] Hikichi, T.; Yanagiya, N.; Kado, M.; Akiba, J.; Yoshida, A. Posterior vitreous detachment induced by injection of plasmin and sulfur hexafluoride in the rabbit vitreous. Retina, 1999, 19(1), 55-58.

[96] Unal, M.; Peyman, G. A. The efficacy of plasminogen-urokinase combination in inducing posterior vitreous detachment. Retina, 2000, 20(1), 69-75.

[97] Asami, T.; Terasaki, H.; Kachi, S.; Nakamura, M.; Yamamura, K.; Nabeshima, T.; Miyake, Y. Ultrastructure of internal limiting membrane removed during plasmin-assisted vitrectomy from eyes with diabetic macular edema. Ophthalmology, 2004, 111(2), 231237.

[98] Margherio, A. R.; Margherio, R. R.; Hartzer, M.; Trese, M. T.; Williams, G. A.; Ferrone, P. J. Plasmin enzyme-assisted vitrectomy in traumatic pediatric macular holes. Ophthalmology, 1998, 105(9), 1617-1620.

[99] Trese, M. T. Enzymatic vitreous surgery. Semin. Ophthalmol., 2000, 15(2), 116-1621.

[100] Hermel, M.; Mahgoub, M.; Youssef, T.; Azrak, M. I.; Raza, H.; Alldredge, C.; Trese, M.; Williams, G. A.; Hartzer, M. Safety profile of the intravitreal streptokinase-plasmin complex as an adjunct to vitrectomy in the rabbit. Graefes Arch. Clin. Exp. Ophthalmol., 2006, 244(8), 996-1002

[101] Scott, I. U. Vitreoretinal surgery for complications of branch retinal vein occlusion. Curr. Opin. Ophthalmol., 2002, 13(3), 161-166.
[102] Met, J. A.; Maberley, A. L.; Richards, S. C. Pars plana vitrectomy for macular degenerative disorders. Can. J. Ophthalmol., 1991, 26(7), 374-376.

[103] Gottlieb, J. L.; Antoszyk, A. N.; Hatchell, D. L.; Saloupis, P. The safety of intravitreal hyaluronidase. A clinical and histologic study. Invest. Ophthalmol. Vis. Sci., 1990, 31(11), 2345-2352.

[104] Harooni, M.; McMillan, T.; Refojo, M. Efficacy and safety of enzymatic posterior vitreous detachment by intravitreal injection of hyaluronidase. Retina, 1998, 18(1), 16-22.

[105] Heegaard, S.; Jensen, O. A.; Prause, J. U. Structure and composition of the inner limiting membrane of the retina. SEM on frozen resin-cracked and enzyme-digested retinas of Macaca mulatta. Graefes Arch. Clin. Exp. Ophthalmol., 1986, 224(4), 355-360.

[106] Nakamura, T.; Yamagata, Y.; Ichishima, E. Nucleotide sequence of the subtilisin NAT gene, aprN, of Bacillus subtilis (natto). Biosci. Biotechnol. Biochem., 1992, 56(11), 1869-1871.

[107] Sumi, H.; Hamada, H.; Tsushima, H.; Mihara, H.; Muraki, H. A novel fibrinolytic enzyme (nattokinase) in the vegetable cheese Natto; a typical and popular soybean food in the Japanese diet. Experientia, 1987, 43(10), 1110-1111.

[108] Sumi, H.; Hamada, H.; Nakanishi, K.; Hiratani, H. Enhancement of the fibrinolytic activity in plasma by oral administration of nattokinase. Acta Haematol., 1990, 84(3), 139-143.

[109] Staubach, F.; Nober, V.; Janknecht, P. Enzyme-assisted vitrectomy in enucleated pig eyes: a comparison of hyaluronidase, chondroitinase, and plasmin. Curr. Eye Res., 2004, 29(4-5), 261-268.

[110] Hermel, M.; Schrage, N. F. Efficacy of plasmin enzymes and chondroitinase $\mathrm{ABC}$ in creating posterior vitreous separation in the pig: a masked, placebo-controlled in vivo study. Graefes Arch. Clin. Exp. Ophthalmol., 2007, 245(3), 399-406.

[111] Gandorfer, A.; Priglinger, S.; Schebitz, K.; Hoops, J.; Ulbig, M.; Ruckhofer, J.; Grabner, G.; Kampik, A. Vitreoretinal morphology of plasmin-treated human eyes. Am. J. Ophthalmol., 2002, 133(1), 156-159.

[112] Ichinose, A.; Takio, K.; Fujikawa, K. Localization of the binding site of tissue-type plasminogen activator to fibrin. J. Clin. Invest., 1986, 78(1), 163-169.

[113] Sasaki, O.; Takeuchi, S.; Koike, T.; Koizumi, T.; Tanaka, R. Fibrinolytic therapy for acute embolic stroke: intravenous, intracarotid, and intra-arterial local approaches. Neurosurgery, 1995, 36(2), 246-252.

[114] Hesse, L.; Chofflet, J.; Kroll, P. Tissue plasminogen activator as a biochemical adjuvant in vitrectomy for proliferative diabetic vitreoretinopathy. Ger. J. Ophthalmol., 1995, 4(6), 323-327.

[115] Gandorfer, A.; Rohleder, M.; Sethi, C.; Eckle, D.; Welge-Lussen, U.; Kampik, A.; Luthert, P.; Charteris, D. Posterior vitreous detachment induced by microplasmin. Invest. Ophthalmol. Vis. Sci. 2004, 45(2), 641-647.

[116] Glacet-Bernard, A.; Kuhn, D.; Vine, A. K.; Oubraham, H.; Coscas, G.; Soubrane, G. Treatment of recent onset central retinal vein occlusion with intravitreal tissue plasminogen activator: a pilot study. Br. J. Ophthalmol., 2000, 84(6), 609-613.

[117] Murakami, T.; Takagi, H.; Kita, M.; Nishiwaki, H.; Miyamoto, K.; Ohashi, H.; Watanabe, D.; Yoshimura, N. Intravitreal tissue plasminogen activator to treat macular edema associated with branch retinal vein occlusion. Am. J. Ophthalmol., 2006, 142(2), 318-320.

[118] Le Mer, Y.; Korobelnik, J. F.; Morel, C.; Ullern, M.; Berrod, J. P. TPA-assisted vitrectomy for proliferative diabetic retinopathy: results of a double-masked, multicenter trial. Retina, 1999, 19(5), 378-382.

[119] Chung, J.; Park, Y. H.; Lee, Y. C. The effect of Nd:YAG laser membranotomy and intravitreal tissue plasminogen activator with gas on massive diabetic premacular hemorrhage. Ophthalmic. Surg. Lasers Imaging, 2008, 39(2), 114-120.

[120] Rizzo, S.; Pellegrini, G.; Benocci, F.; Belting, C.; Baicchi, U.; Vispi, M. Autologous plasmin for pharmacologic vitreolysis prepared 1 hour before surgery. Retina, 2006, 26(7), 792-796.

[121] Wu, W. C.; Drenser, K. A.; Trese, M. T.; Williams, G. A.; Capone, A. Pediatric traumatic macular hole: results of autologous plasmin enzyme-assisted vitrectomy. Am. J. Ophthalmol., 2007, 144(5), 668-672.

[122] Sakuma, T.; Tanaka, M.; Inoue, M.; Mizota, A.; Souri, M.; Ichinose, A. Efficacy of autologous plasmin for idiopathic macular hole surgery. Eur. J. Ophthalmol., 2005, 15(6), 787-794.

[123] Gandorfer, A.; Kampik, A. Enzyme-assisted virectomy in enucleated pig eyes. Curr. Eye Res., 2005, 30(10), 821-822. 
[124] Diaz-Llopis, M.; Udaondo, P.; Arevalo, F.; Salom, D.; GarciaDelpech, S.; Quijada, A.; Romero, F. J. Intravitreal plasmin without associated vitrectomy as a treatment for refractory diabetic macular edema. J. Ocul. Pharmacol. Ther., 2009, 25(4), 379-384.

[125] de Smet, M. D.; Valmaggia, C.; Zarranz-Ventura, J.; Willekens, B. Microplasmin: ex vivo characterization of its activity in porcine vitreous. Invest. Ophthalmol. Vis. Sci., 2009, 50(2), 814-819.

[126] Chen, W.; Mo, W.; Sun, K.; Huang, X.; Zhang, Y. L.; Song, H. Y. Microplasmin degrades fibronectin and laminin at vitreoretinal interface and outer retina during enzymatic vitrectomy. Curr. Eye Res., 2009, 34(12), 1057-1064.

[127] de Smet, M. D.; Gandorfer, A.; Stalmans, P.; Veckeneer, M.; Feron, E.; Pakola, S.; Kampik, A. Microplasmin intravitreal administration in patients with vitreomacular traction scheduled for vitrectomy: the MIVI I trial. Ophthalmology, 2009, 116(7), 13491355,1355 e $1-2$.

[128] Stenn, K. S.; Link, R.; Moellmann, G.; Madri, J.; Kuklinska, E. Dispase, a neutral protease from Bacillus polymyxa, is a powerful fibronectinase and type IV collagenase. J. Invest. Dermatol., 1989, 93(2), 287-290.
[129] Oliveira, L. B.; Meyer, C. H.; Kumar, J.; Tatebayashi, M.; Toth, C. A.; Wong, F.; Epstein, D. L.; McCuen, B. W. 2nd, RGD peptideassisted vitrectomy to facilitate induction of a posterior vitreous detachment: a new principle in pharmacological vitreolysis. Curr. Eye Res., 2002, 25(6), 333-340.

[130] Blankenship, G. W.; Machemer, R. Pars plana vitrectomy for the management of severe diabetic retinopathy: an analysis of results five years following surgery. Ophthalmology, 1978, 85(6), 553559.

[131] Stefansson, E. Oxygen and diabetic eye disease. Graefes Arch. Clin. Exp. Ophthalmol., 1990, 228(2), 120-123.

[132] Holekamp, N. M.; Shui, Y. B.; Beebe, D. C. Vitrectomy surgery increases oxygen exposure to the lens: a possible mechanism for nuclear cataract formation. Am. J. Ophthalmol., 2005, 139(2), 302 310 .

[133] Barbazetto, I. A.; Liang, J.; Chang, S.; Zheng, L.; Spector, A. Dillon, J. P. Oxygen tension in the rabbit lens and vitreous before and after vitrectomy. Exp. Eye Res., 2004, 78(5), 917-924. 